\title{
Apple intake is inversely associated with all-cause and disease-specific mortality in elderly women
}

\author{
Jonathan M. Hodgson ${ }^{1 *}$, Richard L. Prince ${ }^{2,3}$, Richard J. Woodman ${ }^{4}$, Catherine P. Bondonno ${ }^{1}$,
} Kerry L. Ivey ${ }^{5}$, Nicola Bondonno ${ }^{1}$, Eric B. Rimm ${ }^{5}$, Natalie C. Ward ${ }^{1,6}$, Kevin D. Croft ${ }^{1}$ and Joshua R. Lewis ${ }^{7}$

${ }^{1}$ School of Medicine and Pharmacology, Royal Perth Hospital, University of Western Australia, Perth, WA 6000, Australia

${ }^{2}$ School of Medicine and Pharmacology, Sir Charles Gairdner Hospital Unit, University of Western Australia, Nedlands, WA 6009, Australia

${ }^{3}$ Sir Charles Gairdner Hospital, Department of Endocrinology and Diabetes, Nedlands, WA 6009, Australia

${ }^{4}$ School of Public Health, Centre for Epidemiology and Biostatistics, Flinders University of South Australia, Bedford Park,

SA 5042, Australia

${ }^{5}$ Department of Nutrition and Epidemiology, Harvard T. H. Chan School of Public Health, Boston, MA O2115, USA

${ }^{6}$ School of Biomedical Sciences and Curtin Health Innovation Research Institute, Curtin University, Bentley, WA 6102,

Australia

${ }^{7}$ Children's Hospital at Westmead, School of Public Health, Sydney Medical School, University of Sydney, Sydney, NSW 2006, Australia

(Submitted 13 August 2015 - Final revision received 4 November 2015 - Accepted 7 December 2015)

\section{Abstract}

Higher fruit intake is associated with lower risk of all-cause and disease-specific mortality. However, data on individual fruits are limited, and the generalisability of these findings to the elderly remains uncertain. The objective of this study was to examine the association of apple intake with all-cause and disease-specific mortality over 15 years in a cohort of women aged over 70 years. Secondary analyses explored relationships of other fruits with mortality outcomes. Usual fruit intake was assessed in 1456 women using a FFQ. Incidence of allcause and disease-specific mortality over 15 years was determined through the Western Australian Hospital Morbidity Data system. Cox regression was used to determine the hazard ratios (HR) for mortality. During 15 years of follow-up, 607 (41.7\%) women died from any cause. In the multivariable-adjusted analysis, the HR for all-cause mortality was 0.89 (95\% CI $0.81,0.97)$ per SD (53g/d) increase in apple intake, HR 0.80 (95\% CI $0.65,0.98$ ) for consumption of $5-100 \mathrm{~g} / \mathrm{d}$ and HR 0.65 (95\% CI 0.48 , 0.89 ) for consumption of $>100 \mathrm{~g} / \mathrm{d}$ (an apple a day), compared with apple intake of $<5 \mathrm{~g} / \mathrm{d}\left(P_{\text {for trend }}=0.03\right)$. Our analysis also found that higher apple intake was associated with lower risk for cancer mortality, and that higher total fruit and banana intakes were associated lower risk of CVD mortality $(P<0 \cdot 05)$. Our results support the view that regular apple consumption may contribute to lower risk of mortality.

\section{Key words: Apples: Fruits: All-cause mortality: Disease-specific mortality: CVD: Cancer}

Apples are the world's second most consumed fruit after bananas. They are often an important contributor to the intake of dietary components linked with chronic disease prevention, including flavonoids ${ }^{(1,2)}$ and soluble fruit fibre ${ }^{(3)}$. Apples also provide vitamin $\mathrm{C}, \mathrm{K}, \mathrm{Mg}$ and other nutrients ${ }^{(4)}$. Several prospective observational studies have found that apple intake is associated with reduced risk of CVD and specific cancers ${ }^{(5)}$. However, data on the relationship of apple intake with all-cause mortality remain limited ${ }^{(6)}$.

Higher fruit intake is associated with lower risk for all-cause and disease-specific mortality in observational cohort studies ${ }^{(7)}$. Lifestyle change has the potential to substantially reduce the incidence of chronic diseases ${ }^{(8,9)}$. Thus, a key component of recommended lifestyle change is increased consumption of fruits ${ }^{(10,11)}$.

The primary objective of the present study was to determine whether higher intake of apples was associated with a reduced risk of all-cause and disease-specific mortality in a cohort of Australian women aged 70-85 years and followed-up for up to 15 years. We also explored whether any observed relationships were independent of the known protective nutrients present in apples. In secondary analyses, we explored the relationships of other commonly consumed fruits with mortality due to all-causes, CVD and cancer.

\footnotetext{
Abbreviations: HR, hazard ratio; WADLS, Western Australian Data Linkage System.
}

* Corresponding author: J. M. Hodgson, fax +61 89224 0246, email jonathan.hodgson@uwa.edu.au 


\section{Methods}

\section{Study population}

The participants involved in this study were recruited in 1998 to a 5-year, double-blind, randomised controlled trial of daily $\mathrm{Ca}$ supplementation to prevent osteoporotic fracture - the Calcium Intake Fracture Outcome Study - which has been described previously $^{(12)}$. The women were recruited by mail from the Western Australian general population. A random selection of 24800 women aged over 70 years on the electoral roll ( $n$ 33336) received a letter inviting them to join the study. Of the women written to, $5586(22.5 \%)$ responded. Women were excluded if they were receiving bone-active agents including Ca supplements $(22.5 \%)$ or if they had a significant current illness $(3.5 \%)$. Participants were similar in terms of disease burden and medication use by general population of this age but they were more likely to be from higher socio-economic groups $^{(12)}$. At the completion of the trial, subjects were invited to participate in two 5-year follow-up observational studies. All the participants provided their written informed consent, and ethics approval was granted by the Human Ethics Committee of the University of Western Australia and the Human Research Ethics Committee of the Western Australian Department of Health (approval number 2009/24). The study included 1456 women of a total of 1500 women recruited to the study. There were missing dietary data on fifteen women and implausible energy intakes $(<3350$ or $>17575 \mathrm{~kJ} / \mathrm{d})$ for an additional twenty-nine women, leaving 1456 cases for analysis.

\section{Dietary assessment}

At baseline (1998), dietary intake was assessed using a validated semi-quantitative FFQ developed by the Anti-Cancer Council of Victoria ${ }^{(13)}$. Energy and nutrient intakes were estimated based on frequency of consumption and an overall estimate of usual portion size ${ }^{(14)}$. Apple intake and intake of other fruits were assessed and estimated in $\mathrm{g} / \mathrm{d}$ at baseline from separate questions included in the FFQ, which asked 'Over the last 12 months, how many times did you usually eat apples/pears/oranges and other citrus/bananas/etc?'. Flavonoid intake was estimated from data from the FFQ using the United States Department of Agriculture Flavonoid 2.1 databases, described in detail previously ${ }^{(15,16)}$. The intakes of other components present in apples and other fruits that are thought to contribute to their health benefits, including fibre, vitamin $\mathrm{C}, \mathrm{K}$ and $\mathrm{Mg}$, were also derived from the $\mathrm{FFQ}^{(14)}$.

The FFQ was administered at baseline, 5, 7 and 10 years. Movement between the categories of apple intake was a guide to determine the stability of apple intake over time. At 5, 7 and 10 years, a total of twelve of 1190 (1.0\%), ten of $989(1.0 \%)$ and ten of $780(1.3 \%)$ women, respectively, had moved from highest to lowest or lowest to highest apple intake categories, indicating that apple intake for the groups during the follow-up period remained quite stable. Therefore, all the analyses were based on baseline fruit intake alone.

\section{Outcome and covariate assessment}

Mortality data were retrieved from the Western Australian Mortality Database by the Western Australian Data Linkage System (WADLS) for each of the study participants from 1 January 1998 until 31 December 2013. The primary cause of mortality was defined using death certificate data and codes from the International Classification of Diseases, Injuries and Causes of Death Clinical Modification (ICD-9-CM) ${ }^{(17)}$ and the International Statistical Classification of Diseases and Related Health Problems, 10th Revision, Australian Modification (ICD-10-AM) ${ }^{(18)}$. The codes included the following: cardiovascular mortality, ICD-9-CM (390-459) and ICD-10-AM (I00-I99); cancer mortality, ICD-9-CM (140-239 excluding 210-229) and ICD-10-AM (C00-D48 excluding D10-D36); and other causes (all other codes). The primary diagnosis text fields from the death certificate were used to ascertain the cause of death where these coded data were not yet available from the WADLS.

Lifestyle questionnaires were completed by participants at baseline. They obtained information on age, physical activity level and smoking status. The participants provided their previous medical history and current medications verified by their general practitioner. These data were coded using the International Classification of Primary Care-Plus method ${ }^{(19)}$. The coding methodology allows aggregation of different terms for similar pathological entities as defined by the ICD-10 coding system. These data were then used to determine the presence of pre-existing diabetes (T89001-90009). Prevalent CVD was determined from hospital discharge records (1980-1998) retrieved from WADLS for each of the study participants. WADLS provides a complete validated record of every participant's primary diagnosis at hospital discharge using coded data from all hospitals in Western Australia. CVD codes were identified from the International Classification of Diseases, Injuries and Causes of Death Clinical Modification (ICD-9-CM $390-459)^{(17)}$. Prevalent cancer records were retrieved from the Western Australian Cancer registry by WADLS. For physical activity, the women filled in a questionnaire that allowed estimation of energy used during exercise in $\mathrm{kJ} / \mathrm{d}$ using a validated method with published energy costs for specific activities $^{(20,21)}$. The women were asked whether they participated in any sports, recreation or regular physical activities. Women who answered 'no' to this question scored 0 , and women who answered 'yes' were asked to list up to four sports, recreational activities or forms of regular physical activity including walking that were undertaken in the past 3 months. Energy expenditure (in $\mathrm{kJ} / \mathrm{d}$ ) for these activities was calculated using published energy costs. This measure was shown to be associated with bone density ${ }^{(22)}$. Smoking status was coded as non-smoker, ex-smoker (if they had smoked more than one cigarette per day for more than 3 months at any time in their life) or current smoker. Socio-economic status was assessed using relative social advantage related to residential postcodes according to the Australian Bureau of Statistics method ${ }^{(23)}$. This variable was divided into six categories: 1 being the most disadvantaged and 6 being the least disadvantaged. Baseline weight was assessed using digital scales with participants wearing light clothes and no shoes. Baseline height was assessed using a 
stadiometer, and BMI was calculated as $\mathrm{kg} / \mathrm{m}^{2}$. Treatment (placebo/Ca) over the first 5 years was included as a covariate.

\section{Statistical analysis}

Analyses were carried out using IBM SPSS Statistics version 21 (2012IBM Corp.). Statistical significance was set at $P<0.05$ for all tests. Descriptive data are presented as mean values and standard deviations, medians and interquartile ranges or numbers and percentages. Differences in baseline characteristics across categories of apple intake were derived from the ANOVA or Pearson's $\chi^{2}$ test. An analytical protocol was developed before the commencement of analysis. The primary analysis explored relationships of apple intake with mortality outcomes, and secondary analyses explored relationships of total and other individual fruit intake with mortality outcomes. Two models of adjustment were used - age-adjusted model and multivariable-adjusted model (age, BMI, treatment code, smoking status (three levels), socio-economic status (six levels), prevalent diabetes, prevalent CVD, prevalent cancer, use of antihypertensive medication, use of cholesterol-lowering medication, use of low-dose aspirin, physical activity, energy intake and alcohol intake $\left.{ }^{(24)}\right)$. We have also considered additional adjustment beyond the multivariable-adjusted model. First, the potential mediating effects of dietary factors found in apples and other fruits that are linked to chronic disease protection were investigated using further adjustment for intakes of flavonoids, total dietary fibre, $\mathrm{K}, \mathrm{Mg}$ and vitamin C. Second, in separate models, we have adjusted for dietary factors that have been linked with mortality and/or apple intake including SFA intake, total non-apple fruit intake and total vegetable intake. Cox proportional hazard models were used for death outcomes. Initial analyses used apple intake as a continuous variable (presented per SD change in intake). We then used a pre-specified categorical variable with three levels: low, moderate and high. The cut-off values for low intake was $<5 \mathrm{~g} / \mathrm{d}$ (which would equate to an intake of $<20$ apples/year), for moderate intake $5-100 \mathrm{~g} / \mathrm{d}$ and for high intake $>100 \mathrm{~g} / \mathrm{d}$ (which would equate to a small apple each day). We tested for evidence of a linear trend for fruit intakes as continuous variables using the median value for each intake category in separate Cox proportional hazards models. No violations of the Cox proportional hazards assumptions were detected using the global test. Secondary analyses used Cox proportional hazard models to assess associations of intake of total fruit and individual fruits (pears, oranges and other citrus fruits and bananas) as continuous variables (presented per SD change in intake) with all-cause mortality, CVD mortality and cancer mortality.

\section{Results}

\section{Baseline characteristics}

Characteristics of the participants at baseline across apple intake categories are presented in Table 1 . The mean total fruit intake was 244 (SD 129) g/d. Four fruits contributed approximately $75 \%$ of total fruit intake. These included apples (20\%), pears (11\%), oranges and other citrus fruits (23\%) and bananas (21\%). The mean apple intake was 48 (sD 53) g/d. Apple intake
Table 1. Baseline characteristics according to apple intake category (Mean values and standard deviations; medians and interquartile ranges (IQR); numbers and percentages)

\begin{tabular}{|c|c|c|c|c|c|c|c|}
\hline & \multicolumn{6}{|c|}{ Apple intake categories } & \multirow[b]{3}{*}{$P^{*}$} \\
\hline & \multicolumn{2}{|c|}{$<5 \mathrm{~g} / \mathrm{d}$} & \multicolumn{2}{|c|}{$5-100 \mathrm{~g} / \mathrm{d}$} & \multicolumn{2}{|c|}{$>100 \mathrm{~g} / \mathrm{d}$} & \\
\hline & Mean & SD & Mean & SD & Mean & $\mathrm{SD}$ & \\
\hline Number & \multicolumn{2}{|c|}{259} & \multicolumn{2}{|c|}{1004} & \multicolumn{2}{|c|}{193} & \\
\hline Age (years) & $75 \cdot 0$ & $2 \cdot 8$ & $75 \cdot 2$ & 2.7 & $75 \cdot 2$ & $2 \cdot 7$ & 0.54 \\
\hline BMI $\left(\mathrm{kg} / \mathrm{m}^{2}\right)$ & $27 \cdot 3$ & $5 \cdot 1$ & $27 \cdot 1$ & 4.7 & $27 \cdot 6$ & 4.7 & 0.40 \\
\hline Treatment (Ca) & & & & & & & 0.25 \\
\hline$n$ & \multicolumn{2}{|c|}{127} & \multicolumn{2}{|c|}{507} & \multicolumn{2}{|c|}{109} & \\
\hline$\%$ & \multicolumn{2}{|c|}{$49 \cdot 0$} & & $50 \cdot 5$ & & $56 \cdot 5$ & \\
\hline Prevalent CVD & & & & & & & 0.45 \\
\hline$n$ & & 62 & 23 & 39 & & 38 & \\
\hline$\%$ & & 23.9 & & $23 \cdot 8$ & & $19 \cdot 7$ & \\
\hline Prevalent cancer & & & & & & & 0.49 \\
\hline$n$ & & 32 & & 01 & & 18 & \\
\hline$\%$ & & 12.4 & & $10 \cdot 1$ & & 9.3 & \\
\hline Prevalent diabetes $\dagger$ & & & & & & & 0.24 \\
\hline$n$ & & 20 & & 53 & & 14 & \\
\hline$\%$ & & $7 \cdot 7$ & & $5 \cdot 3$ & & $7 \cdot 3$ & \\
\hline Smoking status & & & & & & & $<0.001$ \\
\hline Current smoker & & & & & & & \\
\hline$n$ & & 1 & & 5 & & 1 & \\
\hline$\%$ & & 0.0 & & 0.0 & & 0.0 & \\
\hline Ex-smoker & & & & & & & \\
\hline$n$ & 13 & 32 & 33 & 39 & & 68 & \\
\hline$\%$ & & $51 \cdot 2$ & & 33.8 & & $35 \cdot 2$ & \\
\hline Never smoked & & & & & & & \\
\hline$n$ & 12 & 26 & 65 & 59 & 12 & 24 & \\
\hline$\%$ & & $48 \cdot 6$ & & $65 \cdot 6$ & & $64 \cdot 2$ & \\
\hline Socio-economic status $(1-6)$ & & & & & & & 0.07 \\
\hline 1 Lowest & & & & & & & \\
\hline$n$ & & 19 & & 34 & & 11 & \\
\hline$\%$ & & $7 \cdot 3$ & & $3 \cdot 4$ & & $5 \cdot 8$ & \\
\hline 2 & & & & & & & \\
\hline$n$ & & 36 & 10 & 06 & & 27 & \\
\hline$\%$ & & 13.9 & & $10 \cdot 7$ & & $14 \cdot 1$ & \\
\hline 3 & & & & & & & \\
\hline$n$ & & 45 & 17 & 70 & & 25 & \\
\hline$\%$ & & $17 \cdot 4$ & & $17 \cdot 1$ & & $13 \cdot 1$ & \\
\hline 4 & & & & & & & \\
\hline$n$ & & 30 & 15 & 57 & & 32 & \\
\hline$\%$ & & 11.6 & & $15 \cdot 8$ & & $16 \cdot 8$ & \\
\hline 5 & & & & & & & \\
\hline$n$ & & 47 & 21 & 19 & & 39 & \\
\hline$\%$ & & $18 \cdot 1$ & & $22 \cdot 0$ & & $20 \cdot 4$ & \\
\hline 6 Highest & & & & & & & \\
\hline$n$ & & 32 & 30 & 08 & & 57 & \\
\hline$\%$ & & $31 \cdot 7$ & & 31.0 & & 29.8 & \\
\hline Antihypertensive use & & & & & & & 0.19 \\
\hline$n$ & & 29 & 42 & 21 & & 84 & \\
\hline$\%$ & & $48 \cdot 3$ & & 41.9 & & 43.5 & \\
\hline Statin use & & & & & & & 0.36 \\
\hline$n$ & & 40 & 15 & 94 & & 36 & \\
\hline$\%$ & & $15 \cdot 4$ & & $19 \cdot 3$ & & $18 \cdot 7$ & \\
\hline Low-dose aspirin use & & & & & & & 0.72 \\
\hline$n$ & & 51 & 2 & 14 & & 37 & \\
\hline$\%$ & & $19 \cdot 7$ & & $21 \cdot 3$ & & $19 \cdot 2$ & \\
\hline Physical activity (kJ/d) & & & & & & & 0.65 \\
\hline Median & & 60 & 45 & 58 & 51 & 12 & \\
\hline IQR & $0-\varepsilon$ & 822 & 148 & 851 & 180 & -883 & \\
\hline Energy $(\mathrm{kJ} / \mathrm{d})$ & 67271 & 911 & 71892 & 097 & 83562 & 2471 & $<0.001$ \\
\hline Alcohol intake $(\mathrm{g} / \mathrm{d})$ & & & & & & & 0.03 \\
\hline Median & & $2 \cdot 0$ & & $2 \cdot 0$ & & $1 \cdot 1$ & \\
\hline IQR & $0 \cdot 3-1$ & $12 \cdot 2$ & 0.3 & $-9 \cdot 9$ & $0.1-$ & $-7 \cdot 8$ & \\
\hline SFA (g/d) & $25 \cdot 2$ & $11 \cdot 0$ & $25 \cdot 9$ & 11.6 & $27 \cdot 3$ & $12 \cdot 8$ & 0.15 \\
\hline MUFA (g/d) & 21.5 & $8 \cdot 3$ & $22 \cdot 8$ & $8 \cdot 8$ & $25 \cdot 4$ & $10 \cdot 2$ & $<0.001$ \\
\hline PUFA (g/d) & $9 \cdot 8$ & $4 \cdot 6$ & $11 \cdot 0$ & 4.7 & $12 \cdot 4$ & $5 \cdot 8$ & $<0.001$ \\
\hline
\end{tabular}


Table 1. Continued

\begin{tabular}{|c|c|c|c|c|c|c|c|}
\hline & \multicolumn{6}{|c|}{ Apple intake categories } & \multirow[b]{3}{*}{$P^{*}$} \\
\hline & \multicolumn{2}{|c|}{$<5 \mathrm{~g} / \mathrm{d}$} & \multicolumn{2}{|c|}{$5-100 \mathrm{~g} / \mathrm{d}$} & \multicolumn{2}{|c|}{$>100 \mathrm{~g} / \mathrm{d}$} & \\
\hline & Mean & SD & Mean & SD & Mean & $\mathrm{SD}$ & \\
\hline Total flavonoids (mg/d) & 194 & 127 & 258 & 142 & 426 & 209 & $<0.001$ \\
\hline Dietary fibre $(\mathrm{mg} / \mathrm{d})$ & $19 \cdot 1$ & $7 \cdot 3$ & $322 \cdot 8$ & 37.0 & $30 \cdot 1$ & 8.6 & $<0.001$ \\
\hline Vitamin C (mg/d) & 109 & 58 & 132 & 60 & 171 & 81 & $<0.001$ \\
\hline $\mathrm{K}(\mathrm{mg} / \mathrm{d})$ & 2606 & 744 & 2972 & 802 & 3574 & 954 & $<0.001$ \\
\hline $\mathrm{Mg}(\mathrm{mg} / \mathrm{d})$ & 265 & 86 & 302 & 88 & 359 & 105 & $<0.001$ \\
\hline Pears $(g / d)$ & 15 & 27 & 26 & 31 & 38 & 46 & $<0.001$ \\
\hline Oranges $(g / d)$ & 36 & 60 & 56 & 55 & 75 & 71 & $<0.001$ \\
\hline Bananas $(g / d)$ & 48 & 86 & 51 & 88 & 55 & 105 & 0.25 \\
\hline Total non-apple fruit $(\mathrm{g} / \mathrm{d})$ & 151 & 108 & 199 & 101 & 241 & 102 & $<0.001$ \\
\hline Total fruit $(\mathrm{g} / \mathrm{d})$ & 152 & 108 & 238 & 109 & 395 & 115 & $<0.001$ \\
\hline
\end{tabular}

at baseline was significantly correlated with apple intake at 5 years $(r$ 0.47; $P<0.001), 7$ years $(r \quad 0.43 ; P<0.001)$ and 10 years $(r \quad 0.39 ; P<0.001)$. Significant differences were observed across the categories of apple intake for smoking status and for energy, alcohol, MUFA, PUFA, total flavonoid, dietary fibre, vitamin $\mathrm{C}, \mathrm{K}$ and $\mathrm{Mg}$ intakes.

\section{Apple and other fruit intake and mortality}

Over 15 years of follow-up, 607 (41.7\%) women died from any cause. The primary causes of death in this cohort were CVD ( $n$ 235; 38.7\% of all deaths) and cancer ( $n$ 156; 25.7\% of all deaths). In multivariable-adjusted analyses, each SD increase in apple intake $(53 \mathrm{~g} / \mathrm{d})$ was associated with a reduced risk of death from all-cause (hazard ratio (HR) 0.89; $95 \%$ CI 0.81, 0.97) and cancer (HR 0.81; 95\% CI 0.67, 0.99) but not CVD (HR 0.91; $95 \%$ CI $0.79,1.05$ ) (Fig. 1). The relationship of intakes of total and other individual fruits with all-cause, CVD and cancer mortality were also explored (Fig. 1). In multivariable-adjusted models, higher total fruit and banana intakes were associated with lower risk of CVD mortality $(P<0 \cdot 05)$.

In separate analyses, the relationships of apple intake with the risk of all-cause, CVD and cancer mortality were explored using categories of apple intake. Women who consumed more than the equivalent of a small apple each day $(>100 \mathrm{~g} / \mathrm{d})$ and those with moderate apple consumption (5-100 g/d) were compared with women with low apple consumption $(<5 \mathrm{~g} / \mathrm{d})$ in the 12 months before baseline (Table 2). In multivariableadjusted models, moderate apple consumption was associated with a $20 \%$ lower risk of all-cause mortality, whereas those who ate an apple a day had a $35 \%$ lower risk of all-cause mortality compared with women with low apple consumption (Fig. 2). Further adjustment for total flavonoids, total dietary fibre, $\mathrm{K}, \mathrm{Mg}$ and vitamin $\mathrm{C}$ attenuated the association of apple intake with all-cause mortality $\left(P_{\text {for trend }}=0 \cdot 08\right)$. Similarly, further adjustment for dietary factors that have been linked with mortality and/or apple intake (SFA intake, total non-apple fruit intake and total vegetable intake) also attenuated the association of apple intake with all-cause mortality $\left(P_{\text {for trend }}=0.06\right)$.

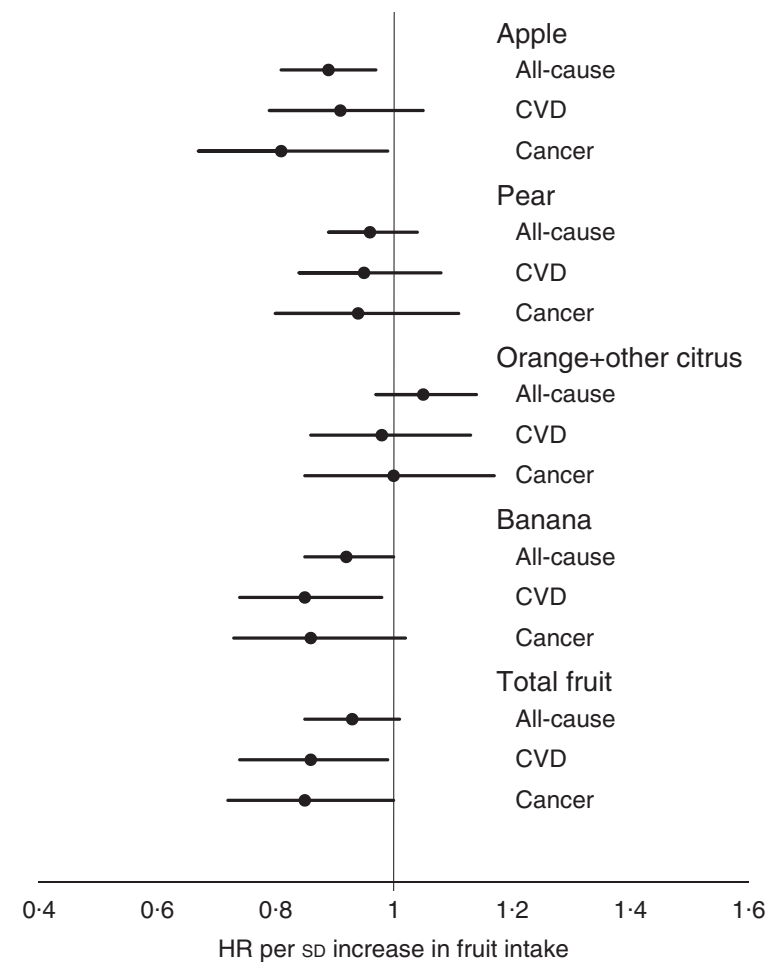

Fig. 1. Multivariable-adjusted hazard ratio (HR) for all-cause mortality ( $n 601)$, CVD mortality $(n 235)$ and cancer mortality $(n 156)$ per sD increase in intake of apple (SD $53 \mathrm{~g} / \mathrm{d}$ ), pear (SD $33 \mathrm{~g} / \mathrm{d}$ ), orange and other citrus fruits (SD $59 \mathrm{~g} / \mathrm{d}$ ), banana (SD $41 \mathrm{~g} / \mathrm{d}$ ) and total fruit (SD $129 \mathrm{~g} / \mathrm{d}$ ). The model included age, BMI, treatment code, smoking status (three levels), socio-economic status (six levels), prevalent diabetes, prevalent CVD, prevalent cancer, use of antihypertensive medication, use of cholesterol-lowering medication, use of low-dose aspirin, physical activity, energy intake and alcohol intake.

Smoking status was markedly different across apple intake categories (Table 1). There was a substantially higher proportion of ex-smokers included in the lowest category of apple intake. The inverse relationship of apple intake with all-cause mortality remained significant after adjustment for smoking status (Fig. 1 and 2). However, we have also explored the relationship of apple intake with all-cause mortality within the non-smoker and ex-smoker groups in separate analyses. In multivariable-adjusted analyses, each SD increase in apple intake $(53 \mathrm{~g} / \mathrm{d})$ was associated with a reduced risk of death from all-causes among the non-smokers (HR 0.86; $95 \%$ CI 0.75, 0.97), but not among the ex-smokers (HR 0.94; $95 \%$ CI 0.82, 1.07). For total fruit intake, each SD increase in apple intake $(129 \mathrm{~g} / \mathrm{d})$ was associated with a reduced risk of death from all-causes among the non-smokers (HR 0.88; 95\% CI 0.79, 0.99), but not among the ex-smokers (HR 0.98; 95\% CI 0.86, 1.11). Results were similar for CVD mortality, but the relationships of both apple and total fruit intake with cancer mortality were comparable for non-smokers and ex-smokers (data not presented).

\section{Discussion}

Higher fruit intakes are associated with lower risk of all-cause mortality $^{(7)}$, but the contribution of specific fruits to these benefits is less clear. Apples, which are the world's second most consumed fruit, often provide a major contribution to total 
Table 2. Hazard ratios (HR) for all-cause, CVD and cancer mortality according to apple intake catergory* (HR and 95\% confidence intervals; numbers and percentages)

\begin{tabular}{|c|c|c|c|c|c|c|}
\hline & \multicolumn{5}{|c|}{ Apple intake categories } & \multirow[b]{3}{*}{$P_{\text {trend }} \dagger$} \\
\hline & $<5 \mathrm{~g} / \mathrm{d}$ & \multicolumn{2}{|c|}{$5-100 \mathrm{~g} / \mathrm{d}$} & \multicolumn{2}{|c|}{$>100 \mathrm{~g} / \mathrm{d}$} & \\
\hline & $95 \% \mathrm{Cl}$ & $\mathrm{HR}$ & $95 \% \mathrm{Cl}$ & $\mathrm{HR}$ & $95 \% \mathrm{Cl}$ & \\
\hline Median intake (g/d) & 1 & \multicolumn{2}{|c|}{34} & \multicolumn{2}{|c|}{136} & \\
\hline Number of women $(n)$ & 259 & \multicolumn{2}{|c|}{1004} & \multicolumn{2}{|c|}{193} & \\
\hline Person-years follow-up (years) & 3167 & \multicolumn{2}{|c|}{12949} & \multicolumn{2}{|c|}{2558} & \\
\hline \multicolumn{7}{|l|}{ All-cause mortality } \\
\hline \multicolumn{7}{|l|}{ Deaths } \\
\hline$n$ & 130 & \multicolumn{2}{|c|}{411} & \multicolumn{2}{|r|}{60} & \\
\hline$\%$ & $50 \cdot 2$ & \multicolumn{2}{|r|}{$40 \cdot 9$} & \multicolumn{2}{|r|}{$34 \cdot 2$} & \\
\hline Age-adjusted & 1.00 & $0.73 \ddagger$ & $0.60,0.89$ & $0.58 \S$ & $0.43,0.78$ & 0.001 \\
\hline Multivariable§ & 1.00 & $0.80 \ddagger$ & $0.65,0.98$ & $0.65 \S$ & $0.48,0.89$ & 0.01 \\
\hline \multicolumn{7}{|l|}{ CVD\| mortality } \\
\hline \multicolumn{7}{|l|}{ Deaths } \\
\hline$n$ & 44 & \multicolumn{2}{|c|}{164} & \multicolumn{2}{|r|}{27} & \\
\hline$\%$ & $17 \cdot 0$ & \multicolumn{2}{|r|}{$16 \cdot 3$} & \multicolumn{2}{|r|}{$14 \cdot 0$} & \\
\hline Age-adjusted & 1.00 & 0.86 & $0.61,1.19$ & 0.68 & $0.42,1.11$ & 0.14 \\
\hline Multivariablell & 1.00 & 0.90 & $0.64,1.26$ & 0.76 & $0.47,1.24$ & 0.30 \\
\hline \multicolumn{7}{|l|}{ Cancer mortality } \\
\hline \multicolumn{7}{|l|}{ Deaths } \\
\hline$n$ & 40 & \multicolumn{2}{|c|}{100} & \multicolumn{2}{|r|}{16} & \\
\hline$\%$ & $15 \cdot 4$ & \multicolumn{2}{|r|}{10.0} & \multicolumn{2}{|r|}{8.3} & \\
\hline Age-adjusted & 1.00 & $0.61 \S$ & $0.42,0.88$ & $0.49 \ddagger$ & $0.28,0.88$ & 0.04 \\
\hline Multivariable§ & 1.00 & $0.65 \ddagger$ & $0.45,0.95$ & $0.53 \ddagger$ & $0.29,0.97$ & 0.08 \\
\hline
\end{tabular}

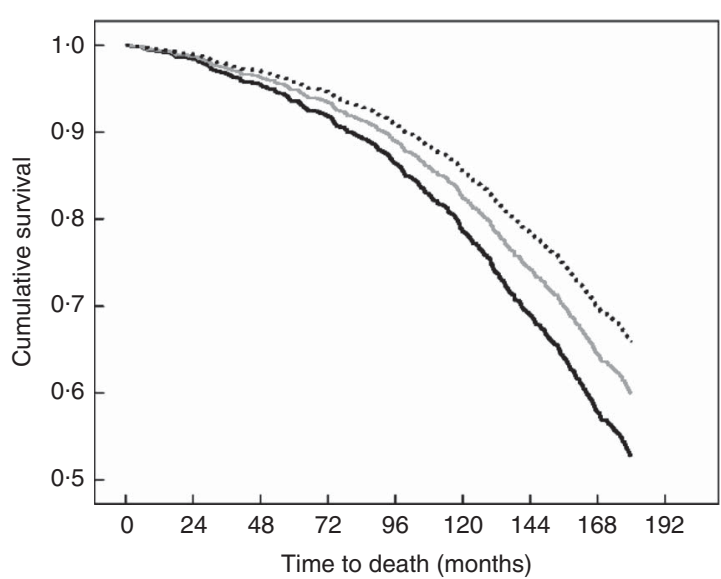

Fig. 2. Multivariable-adjusted hazard ratio (HR) for all-cause mortality ( $n$ 601) for consumption of low $(<5 \mathrm{~g} / \mathrm{d}-------$; HR 1.00 (referent)), moderate $(5-100 \mathrm{~g} / \mathrm{d}-\longrightarrow$; HR $0.80(95 \% \mathrm{Cl} 0.66,0.98 ; P=0.031))$ and high $(>100 \mathrm{~g} / \mathrm{d}-\longrightarrow$; HR $0.65(95 \% \mathrm{Cl} 0.48,0.89 ; P=0.006))$ apple intake. The model included age, BMI $\left(\mathrm{kg} / \mathrm{m}^{2}\right)$, treatment code, smoking status (three levels), socio-economic status (six levels), prevalent diabetes, prevalent CVD, prevalent cancer, use of antihypertensive medication, use of cholesterollowering medication, use of low-dose aspirin, physical activity, energy intake and alcohol intake.

fruit intake. In our cohort, where apple intake provided approximately $20 \%$ of the total fruit intake, we found that higher apple intake was associated with lower all-cause and cancer mortality.
Diets low in fruits were attributed to more than five million deaths in $2010^{(8)}$. A recent meta-analysis including prospective cohort studies found a $6 \%$ risk reduction in all-cause mortality, a $5 \%$ risk reduction in CVD mortality and a non-significant $1 \%$ risk reduction in cancer mortality for each additional serving $(80 \mathrm{~g} / \mathrm{d})$ of fruit. For all-cause mortality, the relationship was linear up to two servings of fruits, after which there was little additional hazard reduction ${ }^{(7)}$. Our analysis found a non-significant $7 \%$ lower risk of mortality from any cause for per SD $(129 \mathrm{~g} / \mathrm{d})$ increase in total fruit intake and a significant 14 and $15 \%$ lower risk of CVD and cancer mortality, respectively. These results are largely consistent with the results of previous studies ${ }^{(7)}$.

There are limited data on the association of apple intake with all-cause mortality ${ }^{(6)}$. We found that the women who consumed $>100 \mathrm{~g} / \mathrm{d}$ of apple had a $35 \%$ lower risk of mortality compared with those who consumed $<5 \mathrm{~g} / \mathrm{d}$. CVD and cancer are the two principal causes of death worldwide. Several previous studies have explored the link between apple intake and risk of CVD or cancer outcomes ${ }^{(5)}$. A higher apple intake is consistently associated with reduced risk of CHD mortality ${ }^{(6,25-28)}$ and incidence of stroke ${ }^{(6,29,30)}$. Observational studies have also linked higher apple intake with reduced risk of lung cancer $^{(6,31-33)}$ and gastrointestinal cancers ${ }^{(34,35)}$. Our results indicate that higher apple intakes are associated with reductions in risk of cancer mortality in the elderly women.

If apples do contribute to reduced risk of dying from a chronic disease, available data indicate that both known and unknown 
food components could be involved. Apples make a contribution to the intake of flavonoids, fibre, vitamin $\mathrm{C}, \mathrm{K}, \mathrm{Mg}$ and several other nutrients $^{(4)}$. The daily consumption of one small apple $(100 \mathrm{~g})$ can provide up to approximately $10 \%$ of the daily intake of total flavonoids and dietary fibre and $2-4 \%$ of the daily intake of vitamin $\mathrm{C}, \mathrm{K}$ and $\mathrm{Mg}$. In this cohort, adjustment for intake of these dietary components minimally changed the observed association of apple intake with mortality, indicating that the association of apple consumption with mortality is only partially mediated by the increased consumption of these nutrients.

Both flavonoid and fibre intakes have been associated with benefits on chronic diseases and their risk factors. Higher intakes of total and specific flavonoids have been associated with reduced risk of $\mathrm{CVD}^{(2,6,25,27)}$, particular cancers ${ }^{(31,36)}$ and all-cause mortality ${ }^{(15)}$. A class of flavonoids consistently related to reduced risk of chronic disease is the flavonols ${ }^{(15,36,37)}$, of which apples often provide a major contribution to overall intake $^{(25-27)}$. The mechanisms by which dietary flavonoids might reduce risk of CVD and cancer are not clearly defined. However, particular flavonoids including the flavonols present in apples enhance nitric oxide status and improve vascular function ${ }^{(38,39)}$. Higher fibre intakes have been associated with lower risk of $\mathrm{CVD}^{(3,40)}$, specific cancers ${ }^{(41)}$ and all-cause mortality ${ }^{(40)}$. There is also evidence that fruit fibre in particular could contribute to these benefits ${ }^{(3,41)}$. Most of the fibre present in apples is pectin, which can reduce circulating cholesterol concentrations $^{(42)}$. Mechanisms of benefit of fruit fibre on specific cancers are less clear. Furthermore, there is evidence that vitamin $\mathrm{C}^{(43)}, \mathrm{K}^{(44)}$ and $\mathrm{Mg}^{(45)}$ could contribute to the health benefits of fruit. However, given that adjustment for these nutrients together with fibre and flavonoids had little impact on multivariate-adjusted effects suggests that there are other potential mechanisms or interactions involved. An additional possible pathway to health benefits of apples involves interaction between flavonoids, fibre and the gastrointestinal microbiota ${ }^{(46,47)}$. There is increasing evidence that the microbiome plays an important role in nutritional determinants of human health ${ }^{(48)}$. We speculate that different fruits could have different effects on the microbiome due to the differences in structural characteristics of fibre, flavonoids and/or other components present.

There are a number of strengths to this study. The long follow-up and resulting high mortality over this time helped increase the power of the study. In addition, mortality outcomes were ascertained using the Western Australian Mortality Database via the WADLS, and therefore all the participants remaining in the state had complete follow-up independent of self-report. Finally, multiple measures of apple consumption were recorded and remained relatively consistent in this cohort over time, suggesting that the observed associations are likely to be a true representation of the relationship between long-term habitual apple intake and mortality.

There are, however, a number of limitations to this study. First, the study included only women, and was an observational study, and thus causality cannot be firmly established. There remains the possibility of residual confounding and selection bias, although the women were mostly representative of the general population. In addition, although the validated FFQ used to assess fruit intake is likely to provide a reasonable estimate of fruit intakes, there will be error in the measurement. Any measurement error would, however, be likely to be non-differential and would therefore only lead to more conservative effect estimates. Furthermore, the questionnaire was not followed-up each year, but multiple measures of apple consumption indicated relatively consistent apple intake in this cohort over time. Finally, although the women recruited to this study are likely to be representative of elderly women at high risk of mortality, additional studies are needed in younger women and in men.

In conclusion, we have shown that a higher apple intake was dose-dependently associated with lower risk of all-cause and cancer mortality in elderly women. Our results support the concept that an apple a day protects against death in elderly women, particularly via reductions in the risk of cancer.

\section{Acknowledgements}

The authors thank the staff at the Data Linkage Branch, Hospital Morbidity Data Collection and Registry of Births, Deaths and Marriages for their work on providing the data for this study.

The study was supported by research grants from Healthway Health Promotion Foundation of Western Australia, Sir Charles Gairdner Hospital Research Advisory Committee and by the project grants 254627, 303169 and 572604 from the National Health and Medical Research Council of Australia. The salary of $\mathrm{J}$. M. H. is supported by a National Health and Medical Research Council of Australia Senior Research Fellowship. The salary of N. C. W. was supported by a MRF/UWA Post-doctoral Fellowship. None of these funding agencies had any input into any aspect of the design and conduct of the study; collection, management, analysis and interpretation of the data; preparation, review or approval of the manuscript; and decision to submit the manuscript for publication. J. M. H., C. P. B. and K. D. C. have received funding support from the Department of Agriculture and Food, Western Australia and Fruit West to support research into the development and evaluation of new apple varieties.

The authors' responsibilities were as follows - J. M. H., R. L. P., R. J. W., C. P. B., N. B., N. C. W., K. D. C. and J. R. L. were responsible for the project conception; J. M. H., R. L. P. and J. R. L. developed the research plan; R. L. P. and J. R. L. collected data; J. M. H., R. J. W. and J. R. L. analysed the data; J. M. H., R. L. P., R. J. W., C. P. B., K. L. I., N. B., E. B. R., N. C. W., K. D. C. and J. R. L. interpreted the data, J. M. H. prepared the manuscript; J. M. H., R. L. P., R. J. W., C. P. B., K. L. I., N. B., E. B. R., N. C. W., K. D. C. and J. R. L. critically reviewed the manuscript. All the authors read and approved the final version of the manuscript. J. M. H. had the primary responsibility for the final content.

None of the other authors has any conflicts of interest.

\section{References}

1. Hodgson JM \& Croft KD (2010) Tea flavonoids and cardiovascular health. Mol Aspects Med 31, 495-502.

2. Hooper L, Kroon PA, Rimm EB, et al. (2008) Flavonoids, flavonoid-rich foods, and cardiovascular risk: a meta-analysis of randomized controlled trials. Am J Clin Nutr 88, 38-50. 
3. Threapleton DE, Greenwood DC, Evans CE, et al. (2013) Dietary fibre intake and risk of cardiovascular disease: systematic review and meta-analysis. BMJ 347, f6879.

4. Hyson DA (2011) A comprehensive review of apples and apple components and their relationship to human health. Adv Nutr 2, 408-420.

5. Boyer J \& Liu RH (2004) Apple phytochemicals and their health benefits. Nutr J 3, 5 .

6. Knekt P, Kumpulainen J, Järvinen R, et al. (2002) Flavonoid intake and risk of chronic diseases. Am J Clin Nutr 76, 560-568.

7. Wang X, Ouyang Y, Liu J, et al. (2014) Fruit and vegetable consumption and mortality from all causes, cardiovascular disease, and cancer: systematic review and dose-response meta-analysis of prospective cohort studies. BMJ 349, g4490.

8. Ezzati M \& Riboli E (2013) Behavioral and dietary risk factors for noncommunicable diseases. $N$ Engl J Med 369, 954-964.

9. Renehan AG \& Howell A (2005) Preventing cancer, cardiovascular disease, and diabetes. Lancet 365, 1449-1451.

10. Liu RH (2013) Health-promoting components of fruits and vegetables in the diet. Adv Nutr $\mathbf{4}, 384 \mathrm{~S}-392 \mathrm{~S}$.

11. Lichtenstein AH, Appel LJ, Brands M, et al. (2006) Diet and lifestyle recommendations revision 2006: a scientific statement from the American Heart Association Nutrition Committee. Circulation 114, 82-96.

12. Prince RL, Devine A, Dhaliwal SS, et al. (2006) Effects of calcium supplementation on clinical fracture and bone structure: results of a 5-year, double-blind, placebo-controlled trial in elderly women. Arch Inter Med 166, 869-875.

13. Hodge A, Patterson AJ, Brown WJ, et al. (2000) The Anti Cancer Council of Victoria FFQ: relative validity of nutrient intakes compared with weighed food records in young to middle-aged women in a study of iron supplementation. Aust $N$ Z JPublic Health 24, 576-583.

14. Ireland P, Jolley D, Giles G, et al. (1994) Development of the Melbourne FFQ: a food frequency questionnaire for use in an Australian prospective study involving an ethnically diverse cohort. Asia Pac J Clin Nutr 3, 19-31.

15. Ivey KL, Hodgson JM, Croft KD, et al. (2015) Flavonoid intake and all-cause mortality. Am J Clin Nutr 101, 1012-1020.

16. Ivey KL, Lewis JR, Prince RL, et al. (2013) Tea and non-tea flavonol intakes in relation to atherosclerotic vascular disease mortality in older women. Br J Nutr 110, 1648-1655.

17. World Health Organization (1977) Manual of the International Statistical Classification of Diseases, Injuries, and Causes of Death: Based on the Recommendations of the Ninth Revision Conference, 1975, and Adopted by the Twenty-Ninth World Health Assembly, 1975 revision edition. Geneva: WHO.

18. World Health Organization (2004) ICD-10 : International Statistical Classification of Diseases and Related Health Problems: Tenth Revision, 2nd ed. Geneva: WHO.

19. Britt H, Scahill S \& Miller G (1997) ICPC PLUS for community health? A feasibility study. Health Inf Manag 27, 171-175.

20. Pollock ML, Wilmore JH \& Fox SM (1978) Health and Fitness Through Physical Activity. New York, NY: Wiley.

21. McArdle WD, Katch FI \& Katch VL (1991) Energy, Nutrition and Human Performance. Philadelphia, PA: Lea \& Febiger.

22. Devine A, Dhaliwal SS, Dick IM, et al. (2004) Physical activity and calcium consumption are important determinants of lower limb bone mass in older women. J Bone Miner Res 19, 1634-1639.

23. Australian Bureau of Statistics (1991) Socio-Economic Indexes for Areas. Canberra: Australian Government Publishing Service.
24. Blekkenhorst LC, Prince RL, Hodgson JM, et al. (2015) Dietary saturated fat intake and atherosclerotic vascular disease mortality in elderly women: a prospective cohort study. Am J Clin Nutr 101, 1263-1268.

25. Knekt P, Jarvinen R, Reunanen A, et al. (1996) Flavonoid intake and coronary mortality in Finland: a cohort study. $\mathrm{Br}$ Med J 312, 478-481.

26. Hertog MGL, Feskens EJM, Kromhout D, et al. (1993) Dietary antioxidant flavonoids and risk of coronary heart disease: the Zutphen Elderly Study. Lancet 342, 1007-1011.

27. Mink PJ, Scrafford CG, Barraj LM, et al. (2007) Flavonoid intake and cardiovascular disease mortality: a prospective study in postmenopausal women. Am J Clin Nutr 85, 895-909.

28. Yochum L, Kushi LH, Meyer K, et al. (1999) Dietary flavonoid intake and risk of cardiovascular disease in postmenopausal women. Am J Epidemiol 149, 943-949.

29. Larsson SC, Virtamo J \& Wolk A (2013) Total and specific fruit and vegetable consumption and risk of stroke: a prospective study. Atherosclerosis 227, 147-152.

30. Griep LMO, Verschuren WM, Kromhout D, et al. (2011) Colors of fruit and vegetables and 10-year incidence of stroke. Stroke 42, 3190-3195.

31. Knekt P, Järvinen R, Seppänen R, et al. (1997) Dietary flavonoids and the risk of lung cancer and other malignant neoplasms. Am J Epidemiol 146, 223-230.

32. Feskanich D, Ziegler RG, Michaud DS, et al. (2000) Prospective study of fruit and vegetable consumption and risk of lung cancer among men and women. J Natl Cancer Inst $\mathbf{9 2}$, 1812-1823.

33. Le Marchand L, Murphy SP, Hankin JH, et al. (2000) Intake of flavonoids and lung cancer. J Natl Cancer Inst 92, 154-160.

34. Freedman ND, Park Y, Subar AF, et al. (2007) Fruit and vegetable intake and esophageal cancer in a large prospective cohort study. Int J Cancer 121, 2753-2760.

35. Gallus S, Talamini R, Giacosa A, et al. (2005) Does an apple a day keep the oncologist away? Ann Oncol 16, 18411844.

36. Hui C, Qi X, Qianyong Z, et al. (2013) Flavonoids, flavonoid subclasses and breast cancer risk: a meta-analysis of epidemiologic studies. PLOS ONE 8, e54318.

37. Huxley RR \& Neil HA (2003) The relation between dietary flavonol intake and coronary heart disease mortality: a metaanalysis of prospective cohort studies. Eur J Clin Nutr 57, 904-908.

38. Bondonno CP, Croft KD, Ward N, et al. (2015) Dietary flavonoids and nitrate: effects on nitric oxide and vascular function. Nutr Rev 73, 216-235.

39. Bondonno CP, Yang X, Croft KD, et al. (2002) Flavonoid-rich apples and nitrate-rich spinach augment nitric oxide status and improve endothelial function in healthy men and women: a randomized controlled trial. Free Radic Biol Med 52, 95-102.

40. Streppel MT, Ocké MC, Boshuizen HC, et al. (2008) Dietary fiber intake in relation to coronary heart disease and all-cause mortality over 40 y: the Zutphen Study. Am J Clin Nutr 88, 1119-1125.

41. Aune D, Chan DS, Lau R, et al. (2011) Dietary fibre, whole grains, and risk of colorectal cancer: systematic review and dose-response meta-analysis of prospective studies. BMJ 343, d6617.

42. Theuwissen E \& Mensink RP (2008) Water-soluble dietary fibers and cardiovascular disease. Physiol Behav 94, 285-292.

43. Kobylecki CJ, Afzal S, Smith GD, et al. (2015) Genetically high plasma vitamin $\mathrm{C}$, intake of fruit and vegetables, and risk of 
ischemic heart disease and all-cause mortality: a Mendelian randomization study. Am J Clin Nutr 101, 1135-1143.

44. Yang Q, Liu T, Kuklina EV, et al. (2011) Sodium and potassium intake and mortality among US adults: prospective data from the Third National Health and Nutrition Examination Survey. Arch Intern Med 171, 1183-1191.

45. Leone N, Courbon D, Ducimetiere P, et al. (2006) Zinc, copper, and magnesium and risks for all-cause, cancer, and cardiovascular mortality. Epidemiology 17, 308-314.
46. Cardona F, Andrés-Lacueva C, Tulipani S, et al. (2013) Benefits of polyphenols on gut microbiota and implications in human health. J Nutr Biochem 24, 1415-1422.

47. Koutsos A, Tuohy KM \& Lovegrove JA (2015) Apples and cardiovascular health-is the gut microbiota a core consideration? Nutrients 7, 3959-3998.

48. Cho I \& Blaser MJ (2012) The human microbiome: at the interface of health and disease. Nat Rev Genet 13, $260-270$ 